\title{
Comparison of real evapotranspiration measured by weighing lysimeters with simulations based on the Penman formula and a crop growth model
}

\author{
Martin Wegehenkel ${ }^{1^{*}}$, Horst H. Gerke ${ }^{2}$ \\ ${ }^{1}$ Institute of Landscape Systems Analysis, Leibniz-Centre for Agricultural Landscape Research (ZALF) Müncheberg, Eberswalder Strasse \\ 84, 15374 Müncheberg. \\ ${ }^{2}$ Institute of Soil Landscape Research, Leibniz-Centre for Agricultural Landscape Research (ZALF) Müncheberg. E-mail: hgerke@zalf.de \\ ${ }^{*}$ Corresponding author. E-mail: mwegehenkel@zalf.de
}

\begin{abstract}
Although the quantification of real evapotranspiration (ETr) is a prerequisite for an appropriate estimation of the water balance, precision and uncertainty of such a quantification are often unknown. In our study, we tested a combined growth and soil water balance model for analysing the temporal dynamics of ETr. Simulated ETr, soil water storage and drainage rates were compared with those measured by 8 grass-covered weighable lysimeters for a 3-year period (January 1, 1996 to December 31, 1998). For the simulations, a soil water balance model based on the Darcy-equation and a physiological-based growth model for grass cover for the calculation of root water uptake were used. Four lysimeters represented undisturbed sandy soil monoliths and the other four were undisturbed silty-clay soil monoliths. The simulated ETr-rates underestimated the higher ETr-rates observed in the summer periods. For some periods in early and late summer, the results were indicative for oasis effects with lysimeter-measured $E T r$-rates higher than corresponding calculated rates of potential grass reference evapotranspiration. Despite discrepancies between simulated and observed lysimeter drainage, the simulation quality for ETr and soil water storage was sufficient in terms of the Nash-Sutcliffe index, the modelling efficiency index, and the root mean squared error. The use of a physiological-based growth model improved the $E T r$ estimations significantly.
\end{abstract}

Keywords: Weighable lysimeters; Modelling; Real evapotranspiration; Drainage; Darcy-equation; Water balance.

\section{INTRODUCTION}

A quantitative determination of real evapotranspiration $(E T r)$ as a component of the water balance is needed for an appropriate management of water resources and understanding of the hydrological cycle (e.g., Budagovskyi and Novák, 2011a, b). Accurate estimates of evapotranspiration are also needed as upper boundary condition for the application of deterministic models to simulate soil water and element fluxes of agricultural and forest ecosystems (e.g. Ficklin et al., 2010; Loos et al., 2007; Luo and Sophocleus, 2010; Soylu et al., 2011). Despite some progress in research and instrumentation, rates of ETr are still difficult to determine experimentally (e.g. Faharani et al., 2007). Micro-meteorological methods to directly measure $E T r$ are based e.g. on eddy-covariance measurements or on surface renewal methods (e.g. Castelvi and Snyder, 2010; Wohlfahrt et al., 2010). Weighable lysimeters measure changes in soil water storage and drainage, which enable the determination of ETr under defined bottom boundary conditions (e.g. Castelvi and Snyder, 2010; Herbst et al., 2005; Loos et al., 2007). In addition to direct measurements, estimation of ETr-rates can be complemented by deterministic modelling approaches. Such modelling systems often consist of modules for the calculation of potential evapotranspiration (ETp) for a reference crop surface (e.g., grass), of crop growth including leaf area index and rooting depth, and of the soil water budget (e.g., based on the Richards' equation) as realized in computer codes such as COUPMODEL (Janson and Karlberg, 2004) and SWAP (Kroes and van Dam, 2003). Despite all enhancements in measurement techniques and models, a precise determination of $E T r$ is still a scientific challenge (e.g. Castelvi and Snyder, 2010; Faharani et al. 2007; Loos et al., 2007; Wohlfahrt et al., 2010).

In a previous study (Wegehenkel et al., 2008), the application of a soil water balance model using a simple empirical approach for $E T r$-calculation resulted in some mismatches between simulated drainage and ETr and those measured by grass-covered weighable lysimeters, which could not fully be explained. As one possible reason for this observed mismatch, inappropriate estimation of ETr of the grass cover by the applied empirical approach was hypothesized in that previous study. Such an inappropriate estimation of $E T r$ was also reported to affect simulated soil water fluxes and to lead to differences between simulated and measured lysimeter drainage in other studies (e.g. Loos et al., 2007). Vegetation type and vegetation growth have a significant impact on the amount of interception and of evapotranspiration and the partitioning into transpiration and evaporation. Computer codes such as the previously mentioned SWAP and COUPMODEL, enabled the simulation of ETr by using physiological-based vegetation growth models for a more appropriate calculation of the impact of vegetation on $E T r$ as compared to empirical estimates of $E T r$ used before. Therefore, one of our objectives was the application of a physiological-based growth model for grass cover for an improvement in the simulation quality of ETr using the same lysimeter data as in the previous study of Wegehenkel et al. (2008). An additional aim was to analyze whether an improvement in the simulation quality of ETr-rates may result in a corresponding improvement of the accuracy of the flux calculations for the lysimeters.

\section{MATERIAL AND METHODS Test site and soils}

The weighable lysimeters were located at the agrometeorological field station Berlin-Dahlem (i.e., $52^{\circ} 28^{\prime} \mathrm{N}$ and $13^{\circ} 18^{\prime}$ E, $51 \mathrm{~m}$ a.s.1.) and were operated by the former Department of Applied Hydrology, Resource Protection, Irrigation, and Drainage of the Technical University of Berlin, Germany. 
The nearby weather station at Dahlem of Germany's National Weather Service (DWD) reported an annual mean air temperature of $9.3^{\circ} \mathrm{C}$ and a mean annual precipitation rate of 545 $\mathrm{mm} \mathrm{y}^{-1}$ for a previous 30-years period 1961-1990 (Diestel et al., 2007; Zenker, 2003). The lysimeters had a surface area of 1 $\mathrm{m}^{2}$ and a depth of $1.5 \mathrm{~m}$. Four lysimeter (lysimeters 1-4) contained intact soil monoliths extracted from a sandy soil. Four undisturbed monoliths extracted from a silty-clay soil (lysimeters 9-12) were fitted in four other lysimeters (Diestel et al., 2007; Zenker, 2003). The lysimeters were installed on even level with the ground surface and placed on stationary balances to register the mass changes of the monoliths with a sensitivity of $100 \mathrm{~g}$. This is equivalent to $0.1 \mathrm{~mm}$ of evapotranspiration or infiltration. Another weighing system measured influx by capillary rise and drainage from the lysimeters. For lysimeters 3 and 4 (sand) and 9 and 10 (silty-clay), a constant water table was imposed at $135 \mathrm{~cm}$ depth; for all other lysimeters, the water table was imposed at $210 \mathrm{~cm}$ depth.

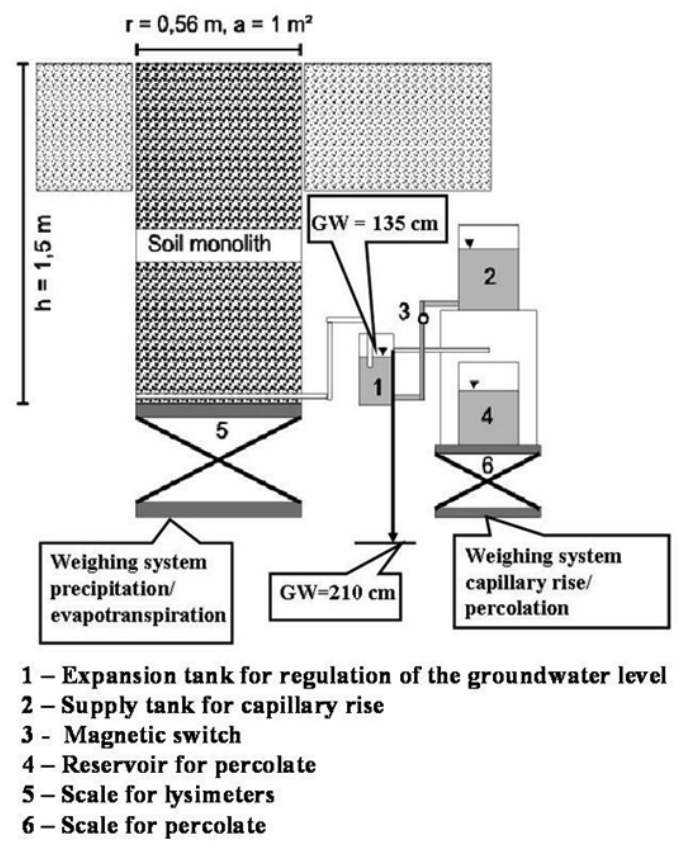

Fig. 1. Lysimeter with groundwater level at $135 \mathrm{~cm}$ depth $(\mathrm{GW}$ $135 \mathrm{~cm}$ ) and at $210 \mathrm{~cm}$ depth $(\mathrm{GW} 210 \mathrm{~cm}$ ) (adapted from Zenker, 2003; modified).

In the present study, we focused on time series of daily rates of ETr, changes in soil water storage, and drainage measured by the lysimeters. The corresponding meteorological data for the time period from January 1, 1996 to December 31, 1998 were measured by an agrometeorological station near the lysimeters. The observed annual precipitation was $534 \mathrm{~mm} \mathrm{y}^{-1}$ in 1996, 497 $\mathrm{mm} \mathrm{y}^{-1}$ in 1997, and $625 \mathrm{~mm} \mathrm{y}^{-1}$ in 1998 (Zenker, 2003). Within this period, the highest daily precipitation rates were measured on May 3, 1996 (56 mm d d $^{-1}$ and on August 14, 1996 (41 $\mathrm{mm} \mathrm{d}^{-1}$ ), and a longer frost period was observed from December 14, 1996 to January 14, 1997 with temperatures down to $-18.1^{\circ} \mathrm{C}$ (Fig. 2). This cold and dry period was without any precipitation or snow accumulation. All lysimeters were covered by grass (i.e., main species Lolium Perenne). Grass cover was mowed 2-3-times per year. More information is given elsewhere (Diestel et al., 2007; Zenker, 2003).

\section{Simulation model}

This model is a combination of a physiological-based grass cover growth model with a multi-layer soil water balance model. Growth of grass cover is simulated with a daily time step using the WOFOST6.0 model (Supit et al., 1994; van Ittersum et al., 2003). As one central part of the WOFOST6.0 model, daily potential grass reference evapotranspiration $(E T p)$ in $\mathrm{mm}$ $\mathrm{d}^{-1}$ is calculated by a modified Penman-approach (Supit et al., 1994):

$$
E T_{p}=\frac{\Delta R_{n a}+\gamma\left(0.26\left(e_{s}-e_{a}\right)(f+u(2))\right.}{\Delta+\gamma},
$$

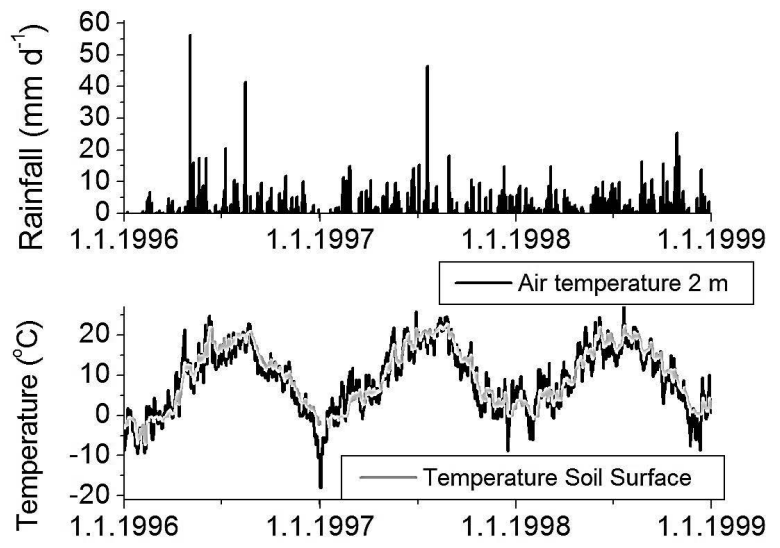

Fig. 2. Daily rates of rainfall in $\mathrm{mm} \mathrm{d}^{-1}$ and air and soil temperature in ${ }^{0} \mathrm{C}$ at the lysimeters, Berlin Dahlem, 1996-1998.

Table 1. Soil physical parameters for the lysimeter soils (from Diestel et al., 2007; modified), $S O M=$ Soil Organic Matter, $p F=\log \mathrm{cm}$ water column.

\begin{tabular}{|c|c|c|c|c|c|c|c|c|c|}
\hline \multicolumn{10}{|c|}{ Lysimeter 1-4, Haplic Podzol $(F A O)$} \\
\hline \multicolumn{6}{|c|}{ Lysimeters 1 and 2, Groundwater at $210 \mathrm{~cm}$ depth } & \multicolumn{4}{|c|}{ Lysimeters 3 and 4 , Groundwater at $135 \mathrm{~cm}$ depth } \\
\hline Horizon & $\begin{array}{l}\text { Depth } \\
\text { (cm) }\end{array}$ & $\begin{array}{l}\text { Sand } \\
(\%)\end{array}$ & $\begin{array}{l}\text { Silt } \\
(\%)\end{array}$ & $\begin{array}{l}\text { Clay } \\
(\%)\end{array}$ & $\begin{array}{c}S O M \\
(\%)\end{array}$ & $\begin{array}{c}\text { Porosity } \\
\left(\mathrm{cm}^{3} \mathrm{~cm}^{-3}\right)\end{array}$ & $\begin{array}{c}\mathrm{pF} 1.8 \\
\left(\mathrm{~cm}^{3} \mathrm{~cm}^{-3}\right)\end{array}$ & $\begin{array}{c}\mathrm{pF} 2.5 \\
\left(\mathrm{~cm}^{3} \mathrm{~cm}^{-3}\right)\end{array}$ & $\begin{array}{c}\mathrm{pF} 4.2 \\
\left(\mathrm{~cm}^{3} \mathrm{~cm}^{-3}\right)\end{array}$ \\
\hline Ap & $0-40$ & 81 & 15 & 4 & 4.0 & 0.427 & 0.230 & 0.165 & 0.050 \\
\hline Bsh1 & $40-60$ & 80 & 15 & 5 & 1.3 & 0.386 & 0.168 & 0.107 & 0.023 \\
\hline Bsh2 & $60-150$ & 87 & 9 & 4 & 0.5 & 0.363 & 0.253 & 0.166 & 0.043 \\
\hline \multicolumn{10}{|c|}{ Lysimeter 9-12, Eutric Cambisol $(F A O)$} \\
\hline \multicolumn{6}{|c|}{ Lysimeters 9 and 10, Groundwater at $135 \mathrm{~cm}$ depth } & \multicolumn{4}{|c|}{ Lysimeters 11 and 12, Groundwater at $210 \mathrm{~cm}$ depth } \\
\hline Ap & $0-20$ & 4 & 67 & 29 & 2.8 & 0.360 & 0.345 & 0.340 & 0.215 \\
\hline Bv1 & $20-60$ & 4 & 69 & 27 & 1.0 & 0.420 & 0.352 & 0.337 & 0.197 \\
\hline Bv2 & $60-150$ & 6 & 75 & 19 & 0.4 & 0.350 & 0.325 & 0.305 & 0.155 \\
\hline
\end{tabular}


where $\Delta$ is the slope of the saturation vapor pressure curve $(\mathrm{kPa}$ $\left.{ }^{\circ} \mathrm{C}^{-1}\right), R_{n a}$ is the net radiation defined as evapotranspiration equivalent $\left(\mathrm{mm} \mathrm{d}^{-1}\right), \gamma$ is the psychrometer constant $=0.67(\mathrm{kPa}$ $\left.{ }^{\circ} \mathrm{C}^{-1}\right), e_{s}$ is the saturated vapour pressure and $e_{a}$ is the actual vapour pressure, both in $\mathrm{kPa}, \mathrm{f}$ is an empirical constant (here: $\mathrm{f}$ $=1.0)$ and $c$ is an empirical coefficient calculated from the difference between daily maximum and minimum air temperature; $u(2)$ is the mean wind speed at $2 \mathrm{~m}$ height $\left(\mathrm{m} \mathrm{s}^{-1}\right)$.

WOFOST describes phenological development and growth of a crop on the basis of crop specific physiological properties and environmental conditions such as weather and soil hydraulic properties. The model simulates biomass accumulation of a crop as a function of intercepted radiation, temperature and crop characteristics. Basis for calculating biomass accumulation is the $\mathrm{CO}_{2}$ canopy assimilation rate, which depends on incoming radiation, light interception of canopy and crop leaf area defined as leaf area index $(L A I)$. From the absorbed radiation and the photosynthetic characteristics of leaves, the daily $\mathrm{CO}_{2}$ crop assimilation rate is calculated. Parts of the carbohydrates produced by assimilation are used to provide energy for maintenance of existing live biomass, which is the maintenance respiration. Remaining carbohydrates are converted into structural matter. Produced biomass matter is partitioned amongst roots, leaves, stems and storage organs, using partitioning factors that are a function of the phenological development stage of the crop. Fraction partitioned to the leaves, determines leaf area development, $L A I$ and hence dynamics of light interception. Phenological development stage is calculated by a heatsum approach as a function of air temperature and day length. An overview of all these processes is presented in Fig. 3.

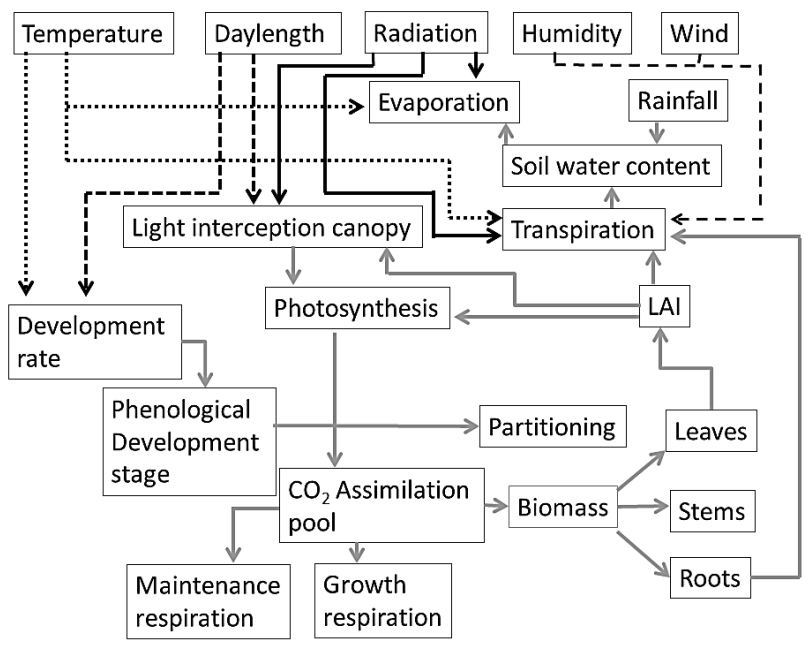

Fig. 3. Diagram of the WOFOST6.0 model, atmospheric inputs in black, interaction in the crop model in gray (van Ittersum et al., 2003; modified).

For each crop, properties such as photosynthetic characteristics of leaves, heat-sum thresholds for e.g. emergence or maturity or initial and maximum rooting depth are defined in a crop parameter file (Supit et al., 1994, van Ittersum et al., 2003). For the simulation of grass cover growth, this maximum rooting depth is assumed to be constant over the total simulation period. In addition to meteorological input data such precipitation, air temperature and humidity, wind speed and global radiation, this crop parameter file is an input for the model calculations. Plant growth is limited by soil water availability, aeration stress, and air temperature stress. Model outputs are e.g. $L A I$, dry matter, rooting depth and plant height. Mowing dates of the grass cover are simulated using defined threshold values of above ground biomass at which it is assumed that grass is being cut and removed. Afterwards, growth starts again and continues until the threshold value for mowing is reached; and then the cycle starts over again.

Rainfall is defined as snow with corresponding snow accumulation, if air temperature falls below a user defined threshold (i.e., we used a value of $+1^{\circ} \mathrm{C}$ ). Snowmelt is calculated by a degree-day approach. Rain interception loss, INT $\left(\mathrm{mm} \mathrm{d}^{-1}\right)$, by the grass cover is simulated by a single linear storage approach according to Koitzsch and Günther (1990). This approach is based on the maximum interception storage capacity, $k$ (i.e., $k$ is between 1.5 and $2.5 \mathrm{~mm}$ for crops and grassland), crop or plant height, $P L H(\mathrm{~m})$, and relative crop soil cover density, $S C D$ (i.e., dimensionless values between 0 and 1 ).

$$
\begin{aligned}
& I N T=k \cdot P L H \cdot S C D \\
& S C D=1-e^{-L A I} .
\end{aligned}
$$

The calculation of $\operatorname{ETr}\left(\mathrm{mm} \mathrm{d}^{-1}\right)$ and the partitioning into transpiration and evaporation is based on the temporal dynamics of $L A I, S C D$, and rooting depth simulated by the grass growth model (Koitzsch and Günther, 1990; Supit et al., 1994).

$$
E T r=\left(\operatorname{ETp} \cdot S C D \cdot \sum_{i=1}^{n} g_{i}\right)+\left(\operatorname{ETp} \cdot(1 \cdot S C D) \cdot \sum_{i=1}^{m} h_{i}\right)
$$

where $g_{i}$ is the fraction of transpiration and $h_{i}$ is the fraction of evaporation extracted from soil layer $i, n$ is the number of soil layers down to the actual rooting depth, and $m$ is the number of soil layers down to evaporation depth. These fractions $g_{i}$ and $h_{i}$ are calculated from

$$
g_{i}=r_{i} \cdot g_{i}^{\prime} \text { and } h_{i}=r_{i} \cdot h_{i}^{\prime}
$$

where $r_{i}$ is a soil layer dependent reduction factor, $g_{i}^{\prime}$ is the fraction of potential water extraction by transpiration, and $h_{i}^{\prime}$ is the fraction of potential water extraction by evaporation. The reduction factor $\left(0 \leq r_{i} \leq 1\right)$ is a function of available soil water $n F C_{i}$ in the layer.

$n F C_{i}=F C_{i} \cdot W P_{i}$

Here, $F C$ is the volumetric water content at field capacity per layer and $W P$ is the corresponding water content at wilting point. If the actual soil water content in one layer is less than a critical layer-dependent soil water content, $\theta c r_{i}$, the value of $r_{i}$ decreases linearly towards zero. Values of $\theta c r_{i}$ and $r_{i}$ for each soil layer are empirically defined according to Koitzsch and Günther (1990) as

$$
x s a_{i}=\frac{x s i \cdot F C_{i}-W P_{i}}{n F C_{i}}
$$

for $E T p>2.5 \mathrm{~mm} \theta c r_{i}=n F C_{i} \cdot\left[x s a_{i}+\left(\frac{1-x s a_{i}}{17.5}\right)-(E T p \cdot 2.5)\right]$

for $E T p \leq 2.5 \quad \theta c r_{i}=n F C_{i} \cdot \frac{x s a_{i}}{2.5} \cdot E T p$ 


$$
\text { for } \theta \leq \theta c r_{i} \quad r_{i}=\frac{\theta_{i}-W P_{i}}{F C_{i}-W P_{i}}
$$

Here, $x s i$ is an empirical parameter in a range from 0.65 to 0.80 , and $x s a$ is an additional empirical parameter depending on $n F C_{i}, F C_{i}$ and $W P_{i}$. For transpiration, $r_{i}$ is zero at the wilting point. For evaporation, $r_{i}$ is zero at air dryness. In the case of transpiration, the function $g_{i}^{\prime}$ describes the spatial distribution of daily water extraction in the root zone between the soil surface $(x=0)$ and the actual rooting depth $(L$ in $\mathrm{dm}, x=L)$. In the case of evaporation, the function $h_{i}{ }_{i}$ describes the water extraction between soil surface and an empirically defined evaporation depth, $E$ (Koitzsch and Günther, 1990)

$$
\begin{aligned}
g_{i}^{\prime}= & \frac{(c+1) \cdot \ln \left(\frac{L \cdot c-x}{L \cdot c+x-1}\right) \cdot \frac{1}{L}}{(c+1) \cdot \ln \left(\frac{c+1}{c}\right)-1} \\
h_{i}^{\prime} & =\frac{(c+1) \cdot \ln \left(\frac{E \cdot c-x}{E \cdot c+x-1}\right) \cdot \frac{1}{E}}{(c+1) \cdot \ln \left(\frac{c+1}{c}\right)-1},
\end{aligned}
$$

where $x$ is the difference between soil surface and the corresponding soil layer $i(\mathrm{dm})$ and $c$ is a parameter for the distribution of water extraction in the soil profile. Here, it is assumed that $c=10$ is for transpiration and $c=20$ as well as $E=1 \mathrm{dm}$ for evaporation (Koitzsch and Günther, 1990).

The soil water balance is calculated using the model SAWAH, which simulates saturated and unsaturated water fluxes in soil profiles and is based on a numerical solution of the flux density and continuity equations (Ten Berge et al., 1995). The flux density $q\left(\mathrm{~cm} \mathrm{~d}^{-1}\right)$ is calculated as follows

$q=-K(h) \cdot \frac{\partial H}{\partial z} \quad$ with $\quad H=h+z$,

where $H$ is the hydraulic potential defined as the sum of soil water matric potential $h$ and the gravitational potential $z$, both in $\mathrm{cm}, K(h)$ is the soil hydraulic conductivity $\left(\mathrm{cm} \mathrm{d}^{-1}\right)$. The changes in soil water contents per time step $\Delta t$ are obtained from the continuity equation

$\frac{\partial \theta}{\partial t}=-\frac{\partial q}{\partial z}+s$ where $s$ is the sink term $\left(\mathrm{cm} \mathrm{d}^{-1}\right)$, and $\theta$ is the soil water content $\left(\mathrm{cm}^{3} \mathrm{~cm}^{-3}\right)$. The soil hydraulic conductivity and water retention functions are described according to the well-known van Genuchten (1980) and Mualem (1976) (vGM)-equations. For unsaturated soil conditions, Eqs (8) and (9) are solved using explicit rectangular integration and a matrix flux potential approach with an internal variable time step ranging from seconds to hours (Ten Berge et al., 1995). However, model outputs are integrated to daily timeframe. For saturated soil conditions, the equations are solved using Crout's implicit method with partial pivoting (Press et al., 1992; Ten Berge et al., 1995). The boundary conditions can be defined as pressure head or daily flux rates at the top and distance to groundwater level or the free drainage at the bottom. The SAWAH model was designed for the calculation of soil water availability for vegetation growth with a maximum of 20 layers for the spatial discretization of the soil profile for the simulations. More details on model application are given elsewhere (e.g., Ten Berge et al., 1995; Wegehenkel, 2005).

\section{Model set up and scenarios}

The simulations with daily time steps were carried out for a period from January 1, 1996 to December 31, 1998. Four model scenarios (see Table 1) were compared: (i) for the lysimeters 12 (sandy soil, water table in $210 \mathrm{~cm}$ depth), (ii) lysimeters 3-4 (sandy soil, water table in $135 \mathrm{~cm}$ depth), (iii) lysimeters 9-10 (silty-clay soil, water table in $135 \mathrm{~cm}$ depth), and (iv) lysimeters 11-12 (silty-clay soil, water table in $210 \mathrm{~cm}$ depth). The soils of the lysimeters were divided in 15 layers each with a thickness of $10 \mathrm{~cm}$ due to the previously-mentioned limitation of the spatial soil profile discretization of 20 layers within the model SAWAH (Ten Berge et al., 1995). The upper boundary of the lysimeters was defined by daily rates of throughfall calculated by the grass cover growth model. At the bottom, a constant water level either at $135 \mathrm{~cm}$ depth or at $210 \mathrm{~cm}$ depth was imposed. The maximum rooting depth of grass was set at $25 \mathrm{~cm}$ and the maximum interception capacity $k$ for grass cover was estimated at $1.5 \mathrm{~mm} \mathrm{~d}^{-1}$ (e.g. Crush et al., 2005). The threshold values of above ground biomass for the initialization of mowing dates were set at $4200 \mathrm{~kg} \mathrm{ha}^{-1}$ (see also Crush et al., 2005).

The parameters of the vGM model (Table 2) for the three soil horizons were obtained from the previous study (Wegehenkel et al., 2008). In that study, vGM-model parameters were interpolated from the $p F$-data in Table 1 using the program SHYPFIT (Durner, 2000). In this interpolation procedure, $\theta_{s}$ was set equal to the highest measured soil water contents (i.e., porosities in Table 1); parameter $\theta_{r}$ was optimized leading to values of $\theta_{r}=0$ for both, sandy and silty-clay soils (Wegehenkel et al., 2008).

Table 2. Van Genuchten-Mualem (= vGM) parameters $\theta_{s}, \theta_{r}, \alpha, n$ and saturated hydraulic conductivity $K_{\text {sat }}$ (from Wegehenkel et al., 2008).

\begin{tabular}{lccccc}
\hline Layer & $\theta_{s}\left(\mathrm{~cm}^{3} \mathrm{~cm}^{-3}\right)$ & $\theta_{r}\left(\mathrm{~cm}^{3} \mathrm{~cm}^{-3}\right)$ & $\alpha\left(\mathrm{cm}^{-1}\right)$ & $n$ & $K_{\text {sat }}\left(\mathrm{cm} \mathrm{d}^{-1}\right)$ \\
\hline Lysimeter 1-4 & & & & & \\
\hline Ap & 0.427 & 0 & 0.072 & 1.665 & 140 \\
Bsh1 & 0.386 & 0 & 0.089 & 1.734 & 221 \\
Bsh2 & 0.363 & 0 & 0.019 & 1.720 & 375 \\
\hline Lysimeter 9-12 & & & & \\
\hline Ap & 0.360 & 0 & 0.002 & 1.142 & 25 \\
Bv1 & 0.420 & 0 & 0.032 & 1.121 & 3 \\
Bv2 & 0.350 & 0 & 0.005 & 1.185 & 5 \\
\hline
\end{tabular}


Initial soil water contents for the simulations were defined as soil water contents at $h=-63 \mathrm{~cm}$ or $p F=1.8$, which corresponded approximately to field capacity. These initial soil water contents were calculated from the water retention function using vGM-parameters from Table 2.

\section{Analysis of model performance}

The goodness of fit between simulated rates of real evapotranspiration, changes in soil water storage, and outflow and the measured data was evaluated using the Nash-Sutcliffe-Index (NS) (Nash and Sutcliffe, 1970)

$$
N S=1-\frac{\sum_{i=1}^{n}\left(\theta_{\text {sim }}-\theta_{o b s}\right)^{2}}{\sum_{i=1}^{n}\left(\theta_{o b s}-\theta_{o b s \_m e a n}\right)^{2}},
$$

the index of agreement (IA) (Willmott, 1982)

$$
I A=1-\frac{\sum_{i=1}^{n}\left(\theta_{\text {sim }}-\theta_{\text {obs }}\right)^{2}}{\sum_{i=1}^{n}\left[\left|\theta_{\text {sim }}-\theta_{\text {obs_mean }}\right|+\left|\theta_{\text {obs }}-\theta_{\text {obs_mean }}\right|\right]^{2}},
$$

and the root mean squared error $(R M S E)$

$R M S E=\sqrt{\frac{\sum_{i=1}^{n}\left(\theta_{\text {sim }}-\theta_{\text {obs }}\right)^{2}}{n}}$,

where $n$ is number of data pairs, $\theta_{\text {obs mean }}$ and $\theta_{\text {sim mean }}$ are the mean values of observed, $\theta_{o b s}$, and simulated, $\theta_{\text {sim }}$, water contents, respectively. The Nash-Sutcliffe-Index ranges between $-\infty$ and 1 . NS-values between 0.0 and 1.0 are generally viewed as acceptable levels of performance, whereas values $<0.0$ indicate that the mean observed value is a better predictor than the simulated value, which is regarded as unacceptable performance (Moriasi et al., 2007). $I A$-values range between 0 and 1 , thus values of $\mathrm{NS}=1$ and $I A=1$ indicate a perfect fit between simulation results and data. According to studies such as that from Legates and McCabe (1999), a complete assessment of model performance should include relative error indices such as NS or $I A$ and absolute error measures such as RMSE.

\section{RESULTS AND DISCUSSION}

Lysimeters 1-4, sandy soils

Soil water storage, evapotranspiration, and leaf area index

At the lysimeter 1, measured daily cumulative changes in soil water storage and those simulated by the model using the maximum grass rooting depth of $25 \mathrm{~cm}$ (Grass 25 in Fig. 2) run mainly similar until July, 1997. After that month, simulated cumulative changes in soil water storage showed a lower depletion in the second half of 1997 and in the summer period 1998 in comparison with those measured by lysimeter 1 (Fig. 4). In contrast to that, since July, 20, 1997 with an observed rainfall of $46 \mathrm{~mm} \mathrm{~d}^{-1}$, daily cumulative changes in soil water storage measured by lysimeter 2 run below those simulated by Grass_25 and those measured by the lysimeters 1 (Fig. 2). This was due to the fact that lysimeter 2 measured no increase in soil water storage due to rainfall observed at July, 20, 1997 (Fig. 4). Corresponding $I A$ was from 0.56 to 0.71 and NS between -0.54 and 0.04 (Table 3 ). This simulated lower depletion of soil water storage in the summer periods 1996 and 1997 was an indication of an underestimation of soil water extraction when using ETr obtained from the model application Grass_25. However, corresponding $I A$ for $E T r$ ranged from 0.83 up to 0.84 , NS-values were between 0.46 and 0.50 , and $R M S E$ within $0.80-0.86 \mathrm{~mm}$ $\mathrm{d}^{-1}$ (Table 4). In order to increase of the soil water extraction out of the root zone of the grass cover by ETr, we applied the model with a maximum rooting depth of $50 \mathrm{~cm}$ (Grass_50). The other crop parameters remained unchanged. This application of Grass 50 had only a small impact on the time series of cumulative changes in soil water storage and, therefore, in a minor improvement of the simulation quality suggested by an $I A$ from 0.60 to 0.78 and a NS from 0.28 to -0.33 (Fig. 4, Table $3)$.

This led to a similar minor improvement of the model performance for ETr indicated by an $I A$ between 0.86 and 0.88 , NS-values from 0.52 up to 0.57 , and RMSE from 0.74 up to $0.81 \mathrm{~mm} \mathrm{~d}^{-1}$ (Fig. 4, Table 4).

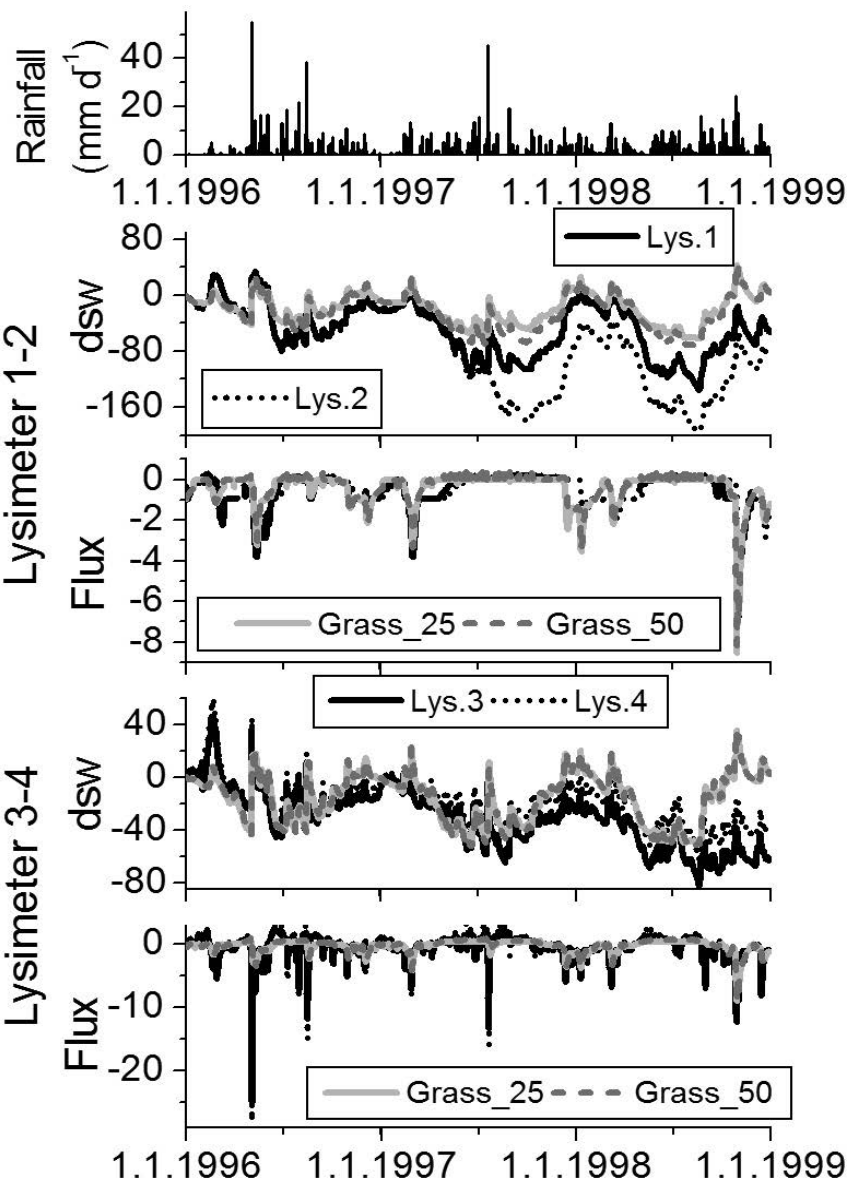

Fig. 4. Daily rates of precipitation (Prc), observed and simulated cumulative changes in soil water storage $(d s w)$ and daily rates of outflow (Flux) for the lysimeters 1-4 all in $\mathrm{mm} \mathrm{d}^{-1}$ calculated by assuming a rooting depth of $25 \mathrm{~cm}$ (Grass_25) and $50 \mathrm{~cm}$ (Grass_50).

At the lysimeters 3-4, the comparison of simulated with observed cumulative changes in soil water storages suggested also 
Table 3. Index of Agreement $I A$, Nash-Sutcliff-Index NS and RMSE obtained from the comparison of measured daily cumulative changes in soil water storage with those simulated with either a rooting depth of $25 \mathrm{~cm}$ (Swc25) or $50 \mathrm{~cm}$ (Swc50), Lysimeters (Lys.) 1-4 and Lysimeters 9-12, Berlin-Dahlem.

\begin{tabular}{cccccccc}
\hline Lys. & $I A$-Swc25 & NS-Swc25 & $\begin{array}{c}R M S E \text {-Swc25 } \\
\left(\mathrm{mm} \mathrm{d}^{-1}\right)\end{array}$ & Lys. & $I A$-Swc25 & NS-Swc25 & $\begin{array}{c}R M S E-S w c 25 \\
\left(\mathrm{~mm} \mathrm{~d}^{-1}\right)\end{array}$ \\
\hline 1 & 0.70 & 0.04 & 37 & 9 & 0.77 & 0.26 & 31 \\
2 & 0.56 & -0.54 & 74 & 10 & 0.83 & 0.52 & 26 \\
3 & 0.63 & -0.38 & 26 & 11 & 0.72 & -0.38 & 48 \\
4 & 0.71 & -0.08 & 19 & 12 & 0.65 & -0.94 & 54 \\
\hline Lys. & $I A$-Swc50 & NS-Swc50 & $\begin{array}{c}R M S E-S w c 50 \\
\left(\mathrm{~mm} \mathrm{~d}^{-1}\right)\end{array}$ & Lys. & $I A-$ Swc50 & NS-Swc50 & $\begin{array}{c}R M S E-S w c 50 \\
\left(\mathrm{~mm} \mathrm{~d}^{-1}\right)\end{array}$ \\
\hline 1 & 0.78 & 0.28 & 32 & 9 & 0.89 & 0.62 & 23 \\
2 & 0.60 & -0.33 & 69 & 10 & 0.92 & 0.75 & 19 \\
3 & 0.63 & -0.40 & 26 & 11 & 0.75 & -0.39 & 49 \\
4 & 0.71 & -0.12 & 19 & 12 & 0.67 & -1.03 & 55 \\
\hline
\end{tabular}

Table 4. Index of Agreement $I A$, Nash-Sutcliff-Index NS and RMSE obtained from the comparison of measured with daily rates of potential grass reference evapotranspiration $(E T p)$, real evapotranspiration rates simulated with either a rooting depth of $25 \mathrm{~cm}(E T r 25)$ or $50 \mathrm{~cm}$ (ETr50), Lysimeters (Lys.) 1-4 and Lysimeters 9-12, Berlin-Dahlem.

\begin{tabular}{|c|c|c|c|c|c|c|c|}
\hline Lys. & $I A-E T p$ & NS-ETp & $\begin{array}{l}R M S E-E T p \\
\left(\mathrm{~mm} \mathrm{~d}^{-1}\right)\end{array}$ & Lys. & $I A-E T p$ & NS-ETp & $\begin{array}{l}\text { RMSE-ETp } \\
\left(\mathrm{mm} \mathrm{d}^{-1}\right)\end{array}$ \\
\hline 1 & 0.94 & 0.73 & 0.58 & 9 & 0.94 & 0.75 & 0.58 \\
\hline 2 & 0.92 & 0.68 & 0.66 & 10 & 0.95 & 0.80 & 0.53 \\
\hline 3 & 0.96 & 0.84 & 0.48 & 11 & 0.94 & 0.76 & 0.57 \\
\hline 4 & 0.97 & 0.87 & 0.47 & 12 & 0.93 & 0.72 & 0.61 \\
\hline Lys. & $I A-E T r 25$ & $N S-E T r 25$ & $\begin{array}{c}R M S E-E T r 25 \\
\left(\mathrm{~mm} \mathrm{~d}^{-1}\right)\end{array}$ & Lys. & $I A-E T r 25$ & NS-ETr 25 & $\begin{array}{c}\text { RMSE-ETr } 25 \\
\left(\mathrm{~mm} \mathrm{~d}^{-1}\right)\end{array}$ \\
\hline 1 & 0.84 & 0.50 & 0.80 & 9 & 0.88 & 0.60 & 0.74 \\
\hline 2 & 0.83 & 0.46 & 0.86 & 10 & 0.87 & 0.58 & 0.77 \\
\hline 3 & 0.86 & 0.57 & 0.79 & 11 & 0.85 & 0.51 & 0.82 \\
\hline 4 & 0.85 & 0.55 & 0.88 & 12 & 0.85 & 0.49 & 0.82 \\
\hline Lys. & $I A-E \operatorname{Tr} 50$ & NS-ETr 50 & $\begin{array}{c}R M S E-E T r 50 \\
\left(\mathrm{~mm} \mathrm{~d}^{-1}\right)\end{array}$ & Lys. & $I A-E \operatorname{Tr} 50$ & NS-ETr 50 & $\begin{array}{l}\text { RMSE-ETr } 50 \\
\left(\mathrm{~mm} \mathrm{~d}^{-1}\right)\end{array}$ \\
\hline 1 & 0.88 & 0.57 & 0.74 & 9 & 0.91 & 0.66 & 0.68 \\
\hline 2 & 0.86 & 0.52 & 0.81 & 10 & 0.90 & 0.66 & 0.70 \\
\hline 3 & 0.91 & 0.69 & 0.67 & 11 & 0.88 & 0.57 & 0.78 \\
\hline 4 & 0.92 & 0.74 & 0.68 & 12 & 0.87 & 0.55 & 0.78 \\
\hline
\end{tabular}

an appropriate simulation in 1996 and 1997 (Fig. 4). After June-July 1998, simulated cumulative changes in soil water storage showed a significant increase in comparison with the lysimeter measurements due to an underestimation of drainage by both modelling approaches in the last months of 1998 (Fig. 4). This led to a low simulation quality for cumulative changes in soil water storage indicated by an $I A$ within $0.63-0.71$ and NS from -0.4 to -0.08 (Table 3 ). However, the model performance for $E T r$ at the lysimeters 3-4 calculated by Grass 25 and Grass_50 was described by an $I A$ from $0.85-0.92$, a NS between 0.55 and 0.74 and RMSE from $0.67-0.88 \mathrm{~mm} \mathrm{~d}^{-1}$ with a better fit of ETr-rates calculated by Grass_50 to the measured ones (Table 3). In the former study using the simple empirical approach for the estimation of daily ETr at the lysimeters 1-4, corresponding $I A$ ranged from 0.71 up to 0.90 and $R M S E$ was from 0.7 up to $1.3 \mathrm{~mm} \mathrm{~d}^{-1}$ (Wegehenkel et al., 2008). In comparison, the application of a physiological-based grass cover growth model increased the simulation quality ( $I A$ was $0.83-$ 0.92 and RMSE 0.6 and $0.9 \mathrm{~mm} \mathrm{~d}^{-1}$, Table 3). In a similar study (Herbst et al., 2005), IA and NS obtained from the comparison of simulated daily ETr-rates with those measured by weighable lysimeters were within $0.93-0.99$ and $0.74-0.96$. Values of NS of 0.78 and $R M S E$ of $0.47 \mathrm{~mm} \mathrm{~d}^{-1}$ were reported in Luo and Sophocleus (2010) and an $I A$ of 0.94 and RMSE of $0.29 \mathrm{~mm} \mathrm{~d}^{-1}$ in Jiang et al. (2008). In a previous investigation using the present data set of lysimeters 3-4 for the application of the soil water balance model SIMWASER (Stenitzer et al., 2007), NS for $E \operatorname{Tr}$ was 0.18 . According to a study of Moriasi et al. (2007), NS $>0.50$ indicated in general a satisfactory, NS $>0.75$ a good simulation quality. Thus, our results for ETr ranged between a satisfactory and a good simulation quality.

Simulated cumulative ETr showed only minor differences between the model application with a rooting depth of $25 \mathrm{~cm}$ and that with a rooting depth of $50 \mathrm{~cm}$ (Grass_25 and Grass_50 in Fig. 5). For the lysimeters 1-2, Grass_25 simulated an amount of cumulative ETr at $1363 \mathrm{~mm}$ and cumulative $E T r$ calculated by Grass_50 was at $1444 \mathrm{~mm}$. For the lysimeters 34, Grass_25 simulated a cumulative ETr at $1404 \mathrm{~mm}$ and Grass_50 calculated a cumulative ETr at $1450 \mathrm{~mm}$ (Fig. 5). Cumulative ETr measured by the lysimeters could not be calculated due to longer gaps in the time series of observed ETr (see Zenker et al., 2003).

Simulated $L A I$ as one essential output of the grass cover growth model controls the partitioning of ETr into transpiration and evaporation and the amount of rainfall water, which is intercepted by the grass canopy (Fig. 6a, b). Similar to the minor differences in ETr between the model application with a rooting depth of $25 \mathrm{~cm}$ (Grass_25) and that with a rooting depth of $50 \mathrm{~cm}$ (Grass 50), only minor differences were observed in the corresponding time series of $L A I$. Therefore, only examples of time series of $L A I$ calculated by Grass_50 are presented for 1996 (Fig. 6a) and 1997 (Fig. 6b). A first check of the model 
plausibility regarding the temporal dynamics of simulated $L A I$ was carried out by comparing simulated with actual mowing dates. Simulated mowing dates indicated by decays of calculated $L A I$ and actual mowing dates of the grass cover were illustrated by black bars (Fig. 6a, b, first graph). This comparison suggested a relatively plausible simulation of the temporal dynamics of $L A I$ at the lysimeters $1-4$. No differences between $L A I$ calculated for the lysimeter 1-2 and $L A I$ simulated for the lysimeters 3-4 were found. Therefore, the observation of relatively similar rainfall interception and soil evaporation for both lysimeters groups seems plausible (Fig. 6a, b).

However, daily rates of potential grass reference evapotranspiration ETp calculated according to Eq. (1) without feedback to soil water availability and to grass cover growth showed the best agreement with ETr-rates measured by the lysimeters $1-4$ (Fig. 7). The corresponding goodness of fit was described by an $I A$ from 0.92 up to 0.97 , NS between 0.68 and 0.87 and a $R M S E$ from 0.58 to $0.66 \mathrm{~mm} \mathrm{~d}^{-1}$ (Table 4).

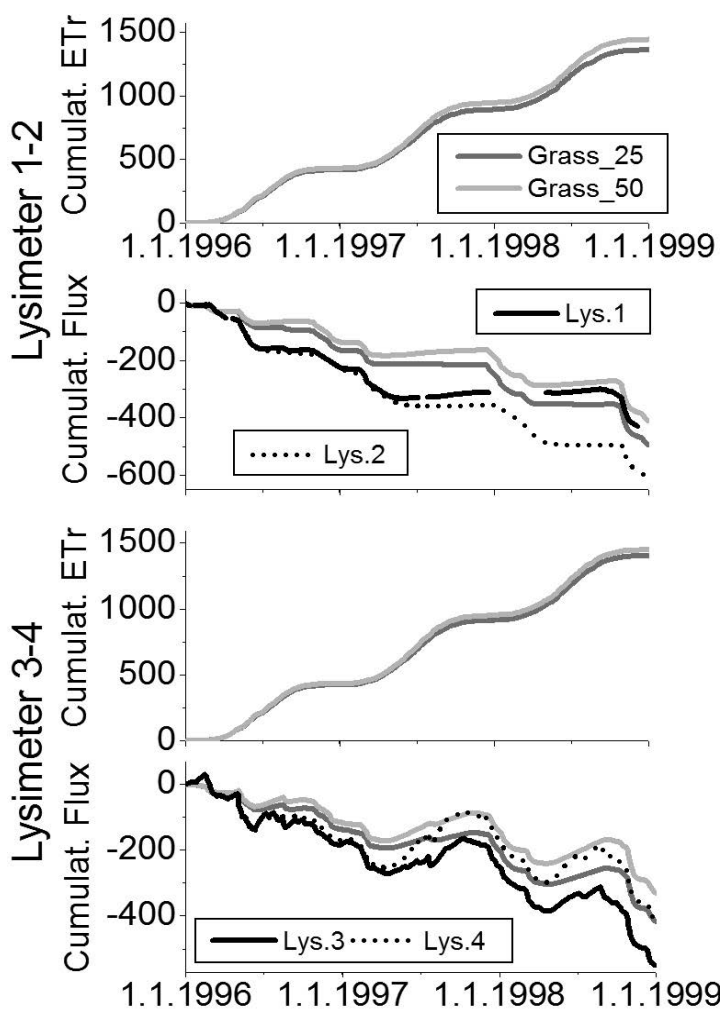

Fig. 5. Cumulative simulated real evapotranspiration $(E T r)$ and drainage (Flux) at the lysimeters 1-2 (upper two graphs) and at the lysimeters 3-4 (lower two graphs) simulated by assuming a rooting depth of $25 \mathrm{~cm}$ (Grass_25) and $50 \mathrm{~cm}$ (Grass_50).

This good agreement between calculated ETp-rates and measured ETr-rates indicated no limitations in soil water availability for root water uptake and evaporation at the lysimeters 1-4. However, a more detailed analysis of ETp, transpiration and evaporation in the summer periods showed that transpiration and evaporation simulated by Grass 25 and Grass 50 were sometimes significantly lower than ETp, thereby indicating limitations in soil water availability for transpiration and evaporation (e.g., end of June 1996 in Fig. 6a). At the beginning of June 1996 and in August 1996, at all lysimeters 1-4 and in June-August 1997 only at the lysimeters 3-4, periods with measured ETr-rates higher than calculated ETp-rates were observed (Fig. 6a, b). This was not observed in 1998. Therefore, only results for 1996 and 1997 are shown in Fig. 6. These results for some shorter summer periods in 1996 and 1997 might be an indication that oasis effects periodically occurred at these lysimeters, while an underestimation or inappropriate calculation of ETp was evaluated as unlikely due to the general good correlation of ETp-rates with those measured by the lysimeters (Fig. 7, Table 3). Oasis effects typically occur if plant and atmospheric conditions of the lysimeters are different from those of the surrounding; either with respect to soil water availability or to canopy wetness of the vegetation cover that could induce an aerodynamic and radiative transfer to the plant canopy of the lysimeter. Net radiation in excess of latent heat is converted in sensible heat that is advected toward the lysimeter. Such net supply of energy to the lysimeter canopy results in an increased ETr (e.g. Rana and Katerij, 2000). However, the lysimeters in our study were not irrigated. On the circumjacent surrounding areas of the lysimeters, also grass cover was established to prevent oasis effects (Diestel et al., 2007). Nevertheless, oasis effects could not be totally excluded at such a lysimeter station as that in Berlin-Dahlem (Zenker, 2003). This was also confirmed by the results of our study.

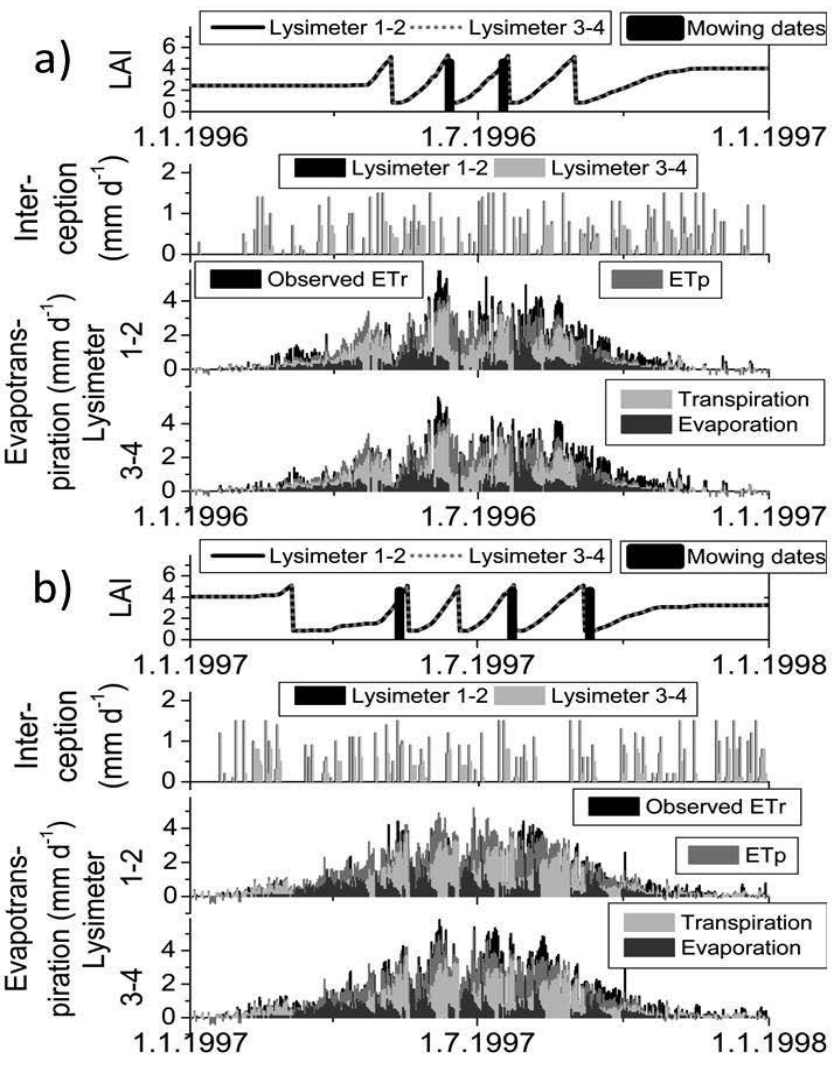

Fig. 6. Leaf area index ( $L A I)$ and mowing dates, interception, potential grass reference evapotranspiration $(E T p)$, observed real evapotranspiration $(E T r)$, transpiration and evaporation in $\mathrm{mm} \mathrm{d}^{-1}$ calculated by assuming a rooting depth of $50 \mathrm{~cm}$ (Grass_50), Lysimeter 1-4, a) 1996 and b) 1997.

\section{Outflow}

Cumulative outflow simulated by both modelling approaches ranged from $-411 \mathrm{~mm}$ to $-496 \mathrm{~mm}$ in contrast to a cumulative drainage of $-622 \mathrm{~mm}$ observed at the lysimeter 2 (Fig. 5). The cumulative drainage of $-427 \mathrm{~mm}$ for the three years period 1996-1998 observed at lysimeter 1 was too low because of gaps in the time series of measured drainage (Fig. 5). Despite this underestimation of cumulative drainage by both modelling 
approaches, simulated daily outflow rates for the lysimeters 1-2 showed a reasonable fit to the measured ones suggested by an $I A$ ranging from 0.86 to 0.92 , NS-values between 0.45 and 0.71 , and a RMSE from 0.50 up to $0.59 \mathrm{~mm} \mathrm{~d}^{-1}$ (Fig. 4 and Table 5).

Daily precipitation rates of $56 \mathrm{~mm} \mathrm{~d}^{-1}$ observed at May 3, 1996, of $41 \mathrm{~mm} \mathrm{~d}^{-1}$ at August 14, 1996 and of $45 \mathrm{~mm} \mathrm{~d}^{-1}$ measured at July, 20, 1997 caused three corresponding outflow peaks between 31 and $13 \mathrm{~mm} \mathrm{~d}^{-1}$ measured in the lysimeters $3-$ 4 , respectively, which were not simulated by the model application with the rooting depth of $25 \mathrm{~cm}$ and that with the rooting depth of $50 \mathrm{~cm}$ (Grass 25 and Grass 50 in Fig. 4). One reason for these discrepancies between drainage observed at the lysimeters 1-2 and outflow measured at the lysimeter 3-4 might be the location of the water tables. This led to unsaturated soil conditions at the lower boundary of the lysimeters 1-2 and to constant saturated soil conditions beginning at a depth of 135 $\mathrm{cm}$ of the soil profiles of the lysimeters 3-4. Thus, the hydraulic conductivity values were generally lower at the bottom of lysimeters 1-2 in contrast to those of lysimeters 3-4 where the daily outflow rates were also larger (Figs 4-5). In addition, the higher water tables in the lysimeters 3-4 led to higher measured rates of capillary rise than those observed for the lysimeters 1-2 (Figs 4-5). This impact of the high water table in the lysimeters 3-4 could, however, not be simulated with our modelling approach using the vGM parameters from Table 2. Therefore, the simulation quality for outflow rates and for cumulative changes in soil water storage was low with an $I A$ from 0.63 up to 0.71 and NS-values between -0.4 and 0.35 (Fig. 4, Tables 3 and 5).

Nevertheless, cumulative outflow at $-416 \mathrm{~mm}$ simulated by Grass_25 was in the same order of magnitude as those measured by the lysimeters 3-4 in a range from -408 to $-550 \mathrm{~mm}$ (Fig. 5). Cumulative drainage simulated by Grass_50 was at $-330 \mathrm{~mm}$ (Fig. 5).

In the previous study, $I A$ for daily drainage simulated at the lysimeters 1-2 was within $0.73-0.86$ and RMSE between $0.7-$ $1.3 \mathrm{~mm} \mathrm{~d}^{-1}$, corresponding $I A$ at the lysimeters 3-4 ranged from 0.78 to 0.81 and $R M S E$ from 1.2 to $1.3 \mathrm{~mm} \mathrm{~d}^{-1}$ (Wegehenkel et al., 2008). Therefore, the application of a physiological-based grass growth model for an improved calculation of ETr resulted also in an increase in the simulation quality for drainage at the lysimeters 1-2 suggested by an $I A$ from 0.86 to 0.92 and a NS between 0.47 and 0.71 (Table 5). In contrast, a decrease in the model performance for drainage at the lysimeters 3-4 was suggested by an $I A$ within 0.61 and 0.67 (Table 4) despite an improvement in the calculation of ETr. In this case, it seemed that inappropriate soil hydraulic parameters or the impact of the lower boundary conditions affected the results more than errors in the calculations of ETr. In two other studies, IA for daily outflow rates was between $0.67-0.98$ and NS showed a wide range from 0.10-0.92 (Herbst et al., 2005; Luo and Sophocleus, 2010). NS-values up to 0.47 were reported for simulated drainage from lysimeters 3-4 in the study of Stenitzer et al. (2007).

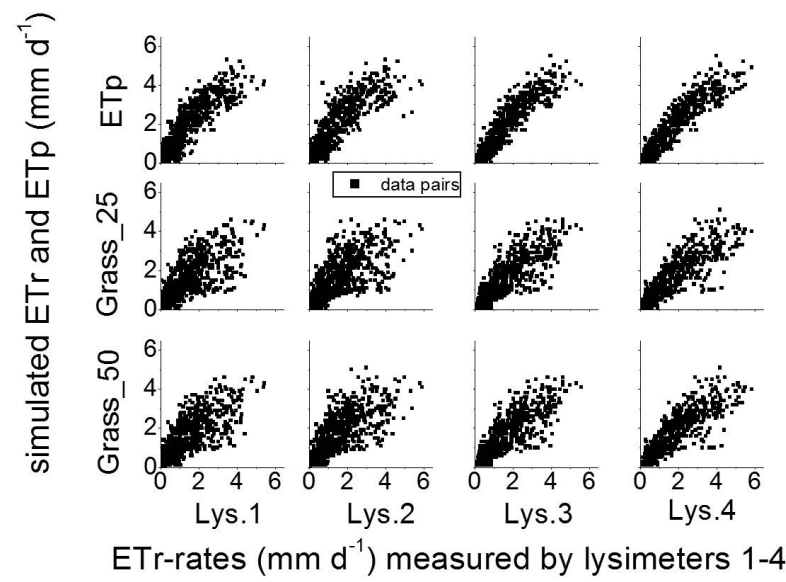

Fig. 7. Comparison of daily rates of potential grass reference evapotranspiration $(E T p)$, of real evapotranspiration simulated by assuming a rooting depth of $25 \mathrm{~cm}\left(E T r_{2} 25\right)$ and $50 \mathrm{~cm}\left(E T r_{-} 50\right)$ with daily rates observed at the lysimeter 1-4 (Lys. 1-4), BerlinDahlem, 1996-1998.

\section{Lysimeters 9-12, silty-clay soils \\ Soil water storage, evapotranspiration, and leaf area index}

Measured and simulated cumulative changes in soil water storage at the lysimeter 9-10 run mainly similar as also suggested by an $I A$ between 0.77 and 0.92 and by a NS from 0.26 to 0.75 (Fig. 8, Table 3). The performance of the model application with the rooting depth of $25 \mathrm{~cm}$ (Grass_25) and of that with the rooting depth of $50 \mathrm{~cm}$ (Grass_50) for the simulation of daily $E T r$ was described by similar values of $I A(0.87-0.91)$ and NS (0.58-0.66; see Table 4). The application of Grass_50 led to a minor increase of the model performance for both, cumulative changes in soil water storage and daily $\operatorname{ETr}$ (Tables 3-4). The cumulative values of ETr of $1289 \mathrm{~mm}$ calculated by Grass_25 and of $1496 \mathrm{~mm}$ simulated with Grass_50 indicate a higher impact of the increased rooting depth for lysimeters 910 as that observed at lysimeters $1-4$ (Fig. 5 and 9).

Table 5. Index of Agreement $I A$, Nash-Sutcliff-Index NS and RMSE obtained from the comparison of measured with daily outflow rates simulated with either a rooting depth of $25 \mathrm{~cm}$ (Flux25) or $50 \mathrm{~cm}$ (Flux50), Lysimeters (Lys.) 1-4 and Lysimeters 9-12, Berlin-Dahlem.

\begin{tabular}{cccccccc}
\hline Lys. & $I A$-Flux25 & NS-Flux25 & $\begin{array}{c}R M S E \text {-Flux25 } \\
\left(\mathrm{mm} \mathrm{d}^{-1}\right)\end{array}$ & Lys. & $I A$-Flux25 & NS-Flux25 & $\begin{array}{c}R M S E \text {-Flux25 } \\
\left(\mathrm{mm} \mathrm{d}^{-1}\right)\end{array}$ \\
\hline 1 & 0.92 & 0.71 & 0.50 & 9 & 0.71 & -0.37 & 1.48 \\
2 & 0.87 & 0.47 & 0.58 & 10 & 0.74 & -0.15 & 1.44 \\
3 & 0.67 & 0.35 & 1.56 & 11 & 0.59 & 0.25 & 1.02 \\
4 & 0.61 & 0.30 & 1.82 & 12 & 0.55 & 0.19 & 1.13 \\
\hline Lys. & $I A$-Flux50 & NS-Flux50 & $\begin{array}{c}R M S E \text {-Flux50 } \\
\left(\mathrm{mm} \mathrm{d}^{-1}\right)\end{array}$ & Lys. & $I A$-Flux50 & NS-Flux50 & $\begin{array}{c}R M S E-F l u x 50 \\
\left(\mathrm{~mm} \mathrm{~d}^{-1}\right)\end{array}$ \\
\hline 1 & & & 0.52 & 9 & 0.77 & -0.02 & 1.27 \\
2 & 0.91 & 0.68 & 0.59 & 10 & 0.79 & 0.15 & 1.24 \\
3 & 0.86 & 0.45 & 1.55 & 11 & 0.52 & 0.16 & 1.09 \\
4 & 0.69 & 0.35 & 1.80 & 12 & 0.48 & 0.10 & 1.21 \\
\hline
\end{tabular}


For lysimeters 11-12, daily cumulative changes of soil water storage simulated with Grass 25 and Grass 50 ranged mainly above the measured values (Fig. 6). This mismatch led to $I A$ values from 0.67 to 0.75 and relatively low NS values between -0.39 and -1.03 (Table 3). Despite this low model performance for cumulative changes of soil water storage, the comparison of daily measured and simulated $E T r$-rates resulted in $I A$ values from 0.85 to 0.88 and NS values between 0.49 and 0.57 for lysimeters 11-12 (Table 4). In contrast to lysimeters 9-10, differences in simulated cumulative ETr at the lysimeters 11-12 of $1409 \mathrm{~mm}$ for Grass $25 \mathrm{~mm}$ and of $1494 \mathrm{~mm}$ for Grass 50 were small and therefore the larger rooting depth had a low impact (Fig. 7).

Similar to the lysimeters $1-4$, time series of simulated $L A I$ showed no or only minor differences within one lysimeter group (9-10 or 11-12) between the model application using the rooting depth of $25 \mathrm{~cm}$ (Grass_25) and that using a rooting depth of $50 \mathrm{~cm}$ (Grass_50). Therefore, only time series of $L A I$ calculated by Grass_50 for 1996 (Fig. 10a) and 1997 (Fig. 10b) are presented again as examples. However, in contrast to the results for the lysimeters $1-4$, the location of the water table at $135 \mathrm{~cm}$ depth in the lysimeter group 9-10 and at $210 \mathrm{~cm}$ depth in the lysimeter group 11-12 had a high impact on the time series of simulated LAI (Fig. 10a, b). The time series of simulated $L A I$ for the lysimeters 11-12 run similar to that calculated for the lysimeters 1-4 (Fig. 6 and 10). The comparison of the simulated mowing dates indicated by decay of calculated $L A I$ with the actual mowing dates marked as black bars suggested also a more or less plausible simulation of $L A I$ (first graph in Fig. 10a, b). However, the development of $L A I$ simulated for the lysimeters 9-10 showed distinct deviations from the other $L A I$-time series. In comparison with those, $L A I$ for the lysimeters 9-10 showed values near zero from January to May and a significant later increase in spring and summer of both years 1996 and 1997 (Fig. 10a, b). This led also to a higher soil evaporation simulated for the lysimeters 9-10 due to relatively small $L A I$-values (Fig. 10a, b).

These low $L A I$-values and the later increase of $L A I$ resulted from simulated aeration stress in the lower part of the root zone between 25 and $50 \mathrm{~cm}$ depths at the lysimeter 9-10 (Fig. 9-11). Aeration stress in the root zone occurs if soil water contents are near saturation. These so called anaerobiosis points are usually defined by a residual soil air content of 1 vol\% or $0.01 \mathrm{~cm}^{3} \mathrm{~cm}^{-3}$ in the root zone. In such a case, the aeration of the root zone becomes deficient for the grass cover that starts reducing transpiration. Such high soil water contents at the lysimeters 9-10 were due to simulated high capillary rise and low calculated drainage and showed a significant impact on the time series of LAI (Fig. 9-11).

Similar to the lysimeters 1-4, daily rates of ETp showed the best agreement with the measured ones with a goodness of fit described by an $I A$ between 0.93 and 0.95 , a NS from 0.72 up to 0.80 , and a RMSE between 0.53 and $0.61 \mathrm{~mm} \mathrm{~d}^{-1}$ (Fig. 12, Table 4). Measured ETr-rates higher than calculated ETp could only be observed at the lysimeters 11-12 in June and August 1996 indicating also the existence of periodical oasis effects (Fig. 10). At the lysimeters 9-10, corresponding observed ETrrates in June and August 1996 were missing due to measurement errors.

Grass_25 showed for ETr an IA between 0.85 and 0.88 and NS from 0.49 to 0.60 , the application of Grass 50 resulted in an $I A$ between 0.87 and 0.91 and NS from 0.55 to 0.66 (Table 4). This indicates also an increase of the simulation quality for $E T r$ in comparison with the previous results with $I A$-values of 0.82
88 for ETr (Wegehenkel et al., 2008). Stenitzer et al. (2007) using the same data set for the lysimeters 9-10, reported lower NS values for $E \operatorname{Tr}$ of 0.17 and 0.18 .

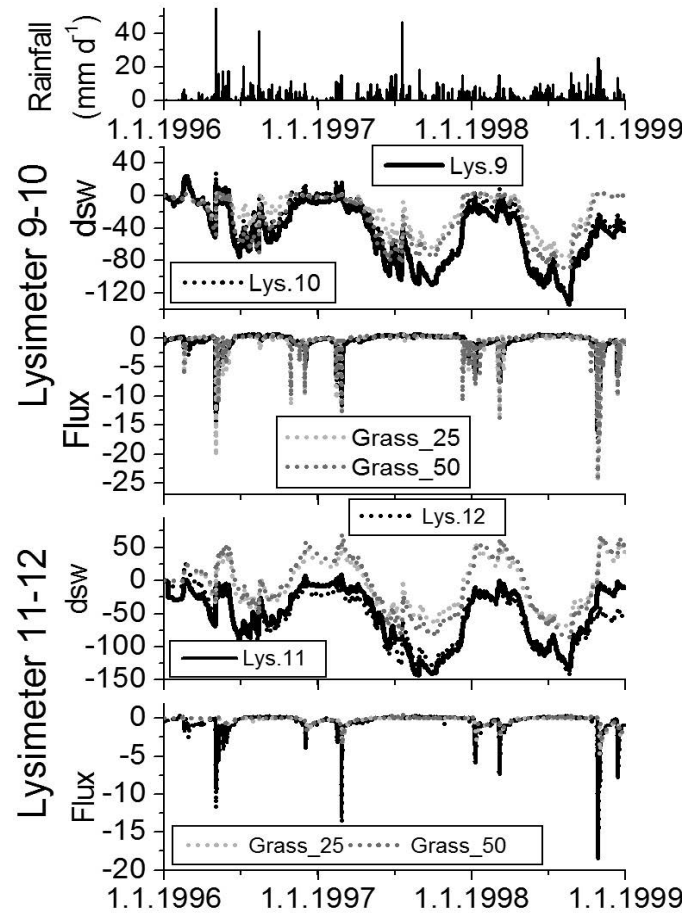

Fig. 8. Daily rates of precipitation $(\operatorname{Prc})$, observed and simulated cumulative changes in soil water storage $(d s w)$ and daily rates of outflow (Flux) for the lysimeters 9-12 (in $\mathrm{mm} \mathrm{d}^{-1}$ ) calculated by assuming a rooting depth of $25 \mathrm{~cm}$ (Grass_25) and $50 \mathrm{~cm}$ (Grass_50).

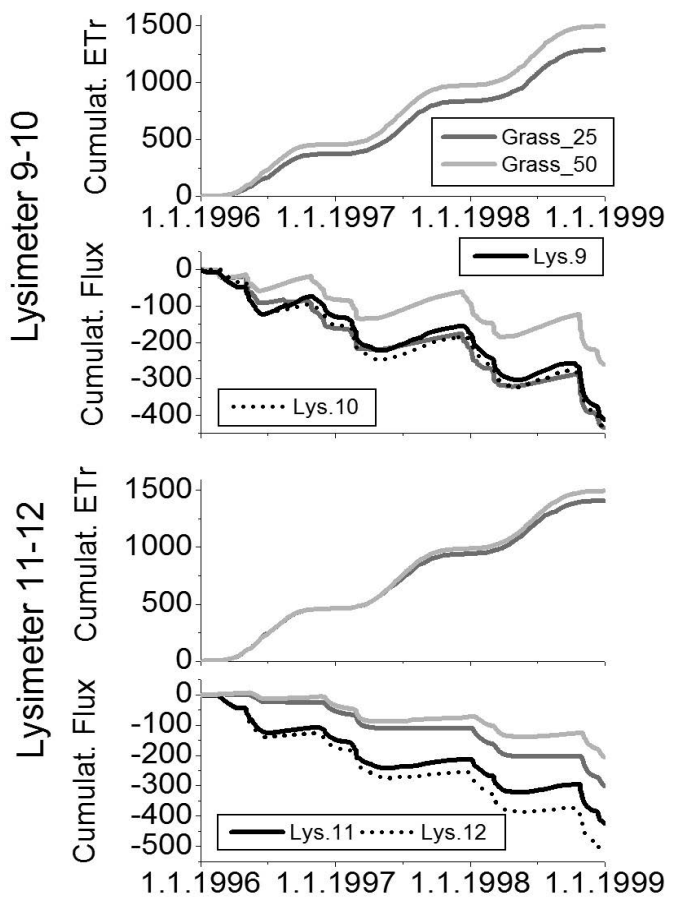

Fig. 9. Cumulative simulated real evapotranspiration $(E T r)$ and drainage (Flux) at the lysimeters 9-10 (upper two graphs) and 1112 (lower two graphs) simulated by assuming a rooting depth of 25 $\mathrm{cm}$ (Grass_25) and $50 \mathrm{~cm}$ (Grass_50). 


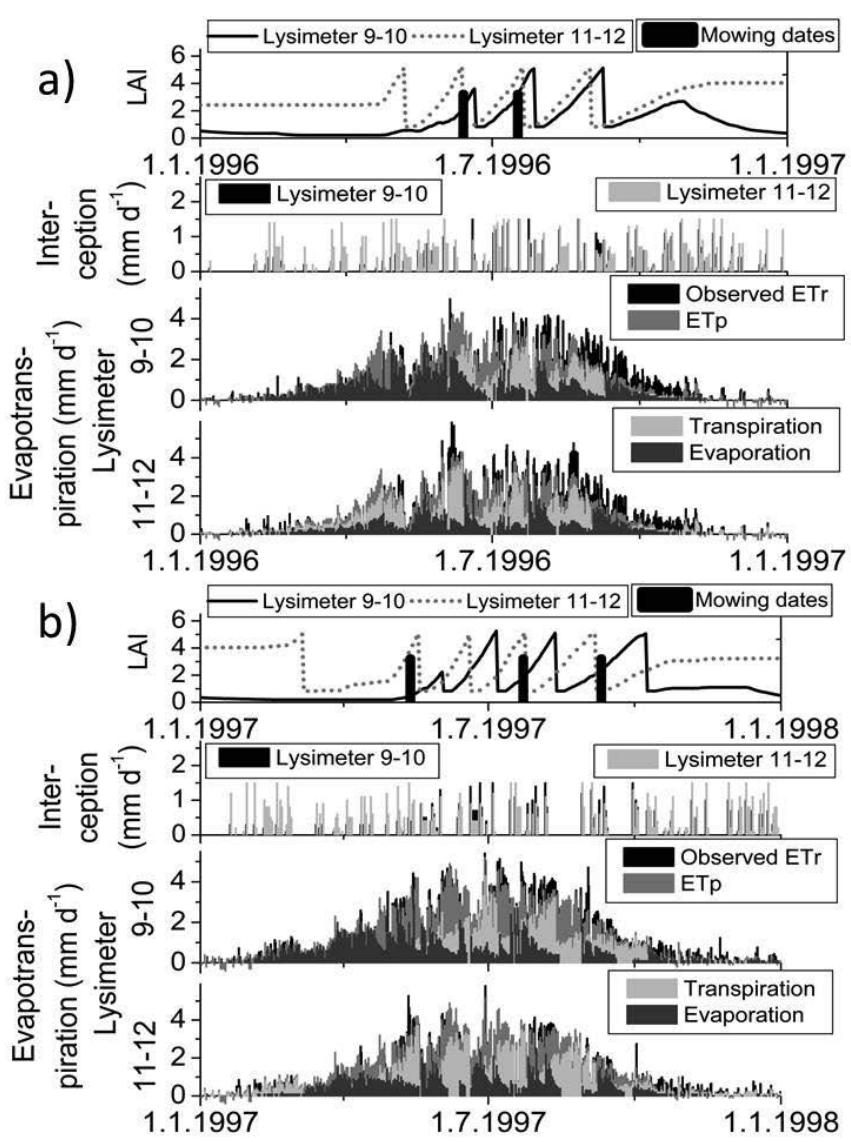

Fig. 10. Leaf area index $(L A I)$ and mowing dates, interception, potential grass reference evapotranspiration $(E T p)$, observed real evapotranspiration $(E T r)$, transpiration and evaporation in $\mathrm{mm} \mathrm{d}^{-1}$ calculated by assuming a rooting depth of $50 \mathrm{~cm}$ (Grass_50) for Lysimeter 9-12; a) 1996 and b) 1997.

\section{Outflow}

At the lysimeters 9-10, the high daily precipitation event observed at May, 3, 1996 and a moist period at the end of 1998 led to high simulated and observed outflow peaks (Fig. 8). Both approaches, the application of the model using a rooting depth of $25 \mathrm{~cm}$ (Grass 25) and that using a rooting depth of $50 \mathrm{~cm}$ (Grass 50) showed over- and underestimation of outflow peaks. Therefore, in contrast to $I A$-values $>0.7$, a NS between -0.37 and -0.02 indicated an insufficient simulation quality of both model applications for drainage (Table 4). Despite this low simulation quality, cumulative drainage of $-435 \mathrm{~mm}$ simulated by Grass 50 was in the same order of magnitude as the measured ones between $-413 \mathrm{~mm}$ and $-435 \mathrm{~mm}$ (Fig. 9). However, Grass_25 simulated only $-261 \mathrm{~mm}$ of cumulative drainage. Here Stenitzer et al. (2007) reported higher NS values for drainage between 0.16 and 0.45 for these lysimeters 9-10.

At the lysimeters 11-12, both Grass_25 and Grass_50 underestimated measured outflow peaks and cumulative drainage and, therefore, simulated daily cumulative changes in soil water storages ranged above the measured ones (Fig. 8). Measured cumulative drainage ranged from -423 and $-529 \mathrm{~mm}$, cumulative outflow simulated by Grass_25 was at $-300 \mathrm{~mm}$ and that calculated by Grass_50 was at $-207 \mathrm{~mm}$. The low simulation quality was reflected by $I A$-values of 0.48 to 0.75 and NSvalues of -1.03 to 0.25 (Tables $4-5$ ), which was even lower than in a previous study, where $I A$ for outflow was $0.66-0.86$ at all lysimeters 9-12 (Wegehenkel et al., 2008). Thus, the ob- served increase in the simulation quality for ETr by using a physiological-based grass growth model had no impact on the model performance for drainage.

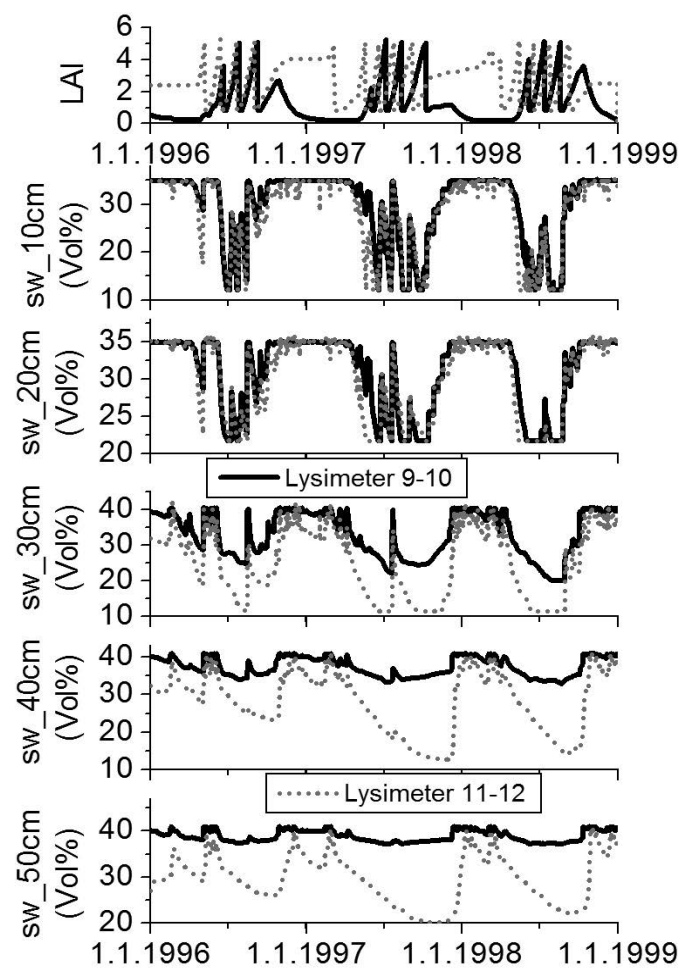

Fig. 11. Leaf area index $(L A I)$ and simulated soil water contents in the compartments $0-10 \mathrm{~cm}$ (sw_10 cm), 10-20 cm (sw 20cm), 20$30 \mathrm{~cm}$ (sw-30cm), 30-40 cm (sw_40 $\mathrm{cm}$ ), and $40-50 \mathrm{~cm}$ (sw_50cm) for Lysimeter 9-12, 1996-1998.

Similar to the lysimeters $3-4$, we assumed that inappropriate soil hydraulic parameters and the impact of the lower boundary conditions affected the simulation results for drainage more than errors in the calculations of ETr.

\section{CONCLUSIONS AND OUTLOOK}

In comparison with the model performance for ETr using a simple empirical approach published in the former study from Wegehenkel et al. (2008), the simulation quality for daily $E T r$ rates and cumulative changes of soil water storage could be improved by using a physiological-based grass cover growth model. Therefore, this model performed well for ETr and soil water storage. The comparison of model outputs such as $L A I$ obtained from the application of this grass cover growth model with a rooting depth of $25 \mathrm{~cm}$ with those simulated with a rooting depth of $50 \mathrm{~cm}$ showed no or only minor differences. This suggested that the rooting depth in the range from $25 \mathrm{~cm}$ to 50 $\mathrm{cm}$ had a minor impact on the grass cover growth model here. However, the good fit between calculated ETp-rates and measured ETr-rates indicated no limitations in soil water availability for evapotranspiration in the lysimeters, although the modelling approach used in our study simulated periods with limitations in soil water availability for ETr. Short time periods with higher observed ETr rates than calculated ETp rates indicated the periodical occurrence of oasis effects, especially at the lysimeters 1-4. Therefore, for the detection of oasis effects, measured ETr should be compared with both, calculated ETp and simulated ETr. This should be considered even if all 
measures and conditions are fulfilled to avoid oasis effects at weighable lysimeters.

Despite a general improvement of the simulation quality of $E T r$ for all lysimeters, an enhancement in the accuracy of the drainage calculations could only be observed for the lysimeters 1-2 with the sandy soil and the water table at $210 \mathrm{~cm}$ depth. For the sandy soil, outflow was mostly significantly higher for saturated conditions in the lysimeter 3-4 where the water table was at $135 \mathrm{~cm}$ depth as compared to unsaturated conditions at the bottom of the lysimeters 1-2. For the silty-clay soil, smaller differences in measured drainage indicate a smaller impact of the lower boundary conditions. Therefore, soil texture- and structure-dependent effects of the lower boundary conditions have to be taken into account in the interpretation of the comparison of measured and simulated soil water fluxes by soil water balance models for weighable lysimeters.

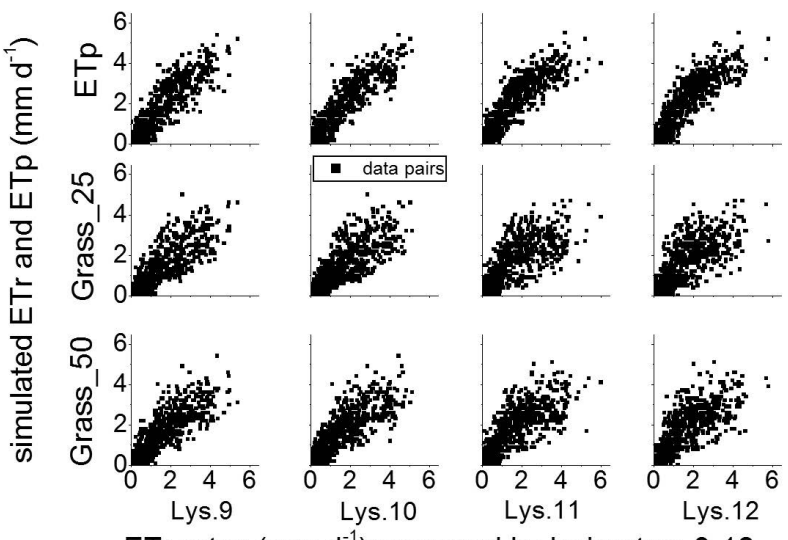

Fig. 12. Comparison of daily rates of potential grass reference evapotranspiration (ETp), of real evapotranspiration simulated by assuming a rooting depth of $25 \mathrm{~cm}(E \operatorname{Tr} 25)$ and $50 \mathrm{~cm}(E T r \quad 50)$ with daily rates observed at the lysimeter 9-12 (Lys. 9-12), BerlinDahlem, 1996-1998.

The results of the applied soil water balance model suggest that calculations of the timing and amount of outflow peaks and cumulative drainage still remain limited when using nonoptimized vGM-parameters, despite an improvement of the simulation quality of $E T r$ by using a physiological-based grass cover growth model. The impact of the bottom boundary conditions on the drainage at the lysimeters 3-4 and 9-12 could not be sufficiently described without calibration of the soil hydraulic functions. Thus, for more detailed future analysis of flow in these weighable lysimeters, the soil hydraulic model parameters should be optimized and soil water movement simulated with more sophisticated numerical simulation models.

Acknowledgements. This study was financially supported by the German Federal Ministry of Consumer Protection, Food and Agriculture and the Ministry of Agriculture, Environmental Protection and Regional Planning of the Federal State of Brandenburg (Germany). We have to thank Dr. Thomas Zenker and Prof. Dr. Heiko Diestel from the former Department of Applied Hydrology, Resource Protection, Irrigation, and Drainage of the Technical University of Berlin, Germany for providing the lysimeter data set. We have to thank Germany's National Weather Service (DWD) for providing data of the station Berlin-Dahlem.

\section{REFERENCES}

Budagovskyi, A.I., Novák, V., 2011a. Theory of evapotranspiration: 1.Transpiration and its quantitative description. J. Hydrol. Hydromech., 59, 1, 3-23.

Budagovskyi, A.I., Novák, V., 2011b. Theory of evapotranspiration: 2. Soil and intercepted water evaporation. J. Hydrol. Hydromech., 59, 2, 73-84.

Castellvi, F., Snyder, R.L., 2010. A comparison between latent heat fluxes over grass using a weighing lysimeter and surface renewal analysis. J. Hydrol., 381, 213-220.

Crush, J.R., Waller, J.E., Care, D.A., 2005. Root distribution and nitrate interception in eleven temperate forage grasses. Grass Forage Sci., 60, 385-392.

Diestel, H., Zenker, T., Schwartengraeber, R., Schmidt, M., 2007. The Lysimeter Station at Berlin-Dahlem. In: Kersebaum, K.C., Hecker, J.M., Mirschel, W., Wegehenkel, M. (Eds.): Modelling Water and Nutrient Dynamics in Soil Crop Systems. Springer, 259-267.

Durner, W., 2000. SHYPFIT 0.22 Users manual. Research Report 95.1, Department of Hydrology, University of Bayreuth, Bayreuth.

Faharani, H.J., Howell, T.A., Shuttleworth, W.J., Bausch, W.C., 2007. Evapotranspiration; Progress in measurement and modelling in agriculture. T. ASABE, 50(5), 1627-1638.

FAO-Unesco, 1988. Soil Map of the World. Food and Agriculture Organization of the United Nations, Rom., 119 pp.

Ficklin, D.L., Luedelinga, E., Zhang, M., 2010. Sensitivity of groundwater recharge under irrigated agriculture to changes in climate, $\mathrm{CO}_{2}$ concentrations and canopy structure. Agr. Water Manage., 97, 1039-1050.

Herbst, M., Fialkiewicz, W., Chen, T., Pütz, T., Thiery, D., Mouvet, C., Vachaud, G., Vereecken, H., 2005. Intercomparison of flow and transport models applied to vertical drainage in cropped lysimeters. VZJ, 4, 240-254.

Jansson, P.E., Karlberg, L., 2004. Coupled heat and mass transfer model for soil-plant-atmosphere systems. ftp://www.lwr.kth.se/CoupModel/CoupModel.pdf. Royal Institute of Technology, Dept. of Civil and Environmental Engineering, Stockholm.

Jiang, J., Zhang, Y., Wegehenkel, M., Yu, Q., Xia, J., 2008. Estimation of soil water contents and evapotranspiration from irrigated cropland on the North China Plain. J. Plant Nutr. Soil Sc., 171, 751-761.

Koitzsch, R., Günther, R., 1990. Simulation model for the calculation of continuous time series of evapotranspiration and soil moisture of agricultural fields. Arch. Acker Pfl. Boden., 24, 717-725. (In German.)

Kroes, J.G., van Dam, J.C. (Eds.), 2003. Reference Manual SWAP version 3.0.4. Wageningen, Alterra, Green World Research, Alterra-Report, 773, Wageningen, The Netherlands, $211 \mathrm{pp}$.

Legates, D.R., McCabe, G.J., 1999. Evaluating the use of "goodness of fit" measures in hydrologic and hydroclimatic model evaluation. Water Resources Research, 35, 233-241.

Loos, C., Gayler, S., Priesack, S., 2007. Assessment of water balance simulations for large scale weighing lysimeters. J. Hydrol., 335(3-4), 259-270.

Luo, Y., Sophocleous, M., 2010. Seasonal groundwater contribution to crop-water use assessed with lysimeter observations and model simulations. J. Hydrol., 389, 325-335.

Moriasi, D.N., Arnold, J.G., van Liew, M.W., Bingner, R.L., Harmel, R.D., Veith, T.L., 2007. Model Evaluation Guidelines for Systematic Quantification of Accuracy in Watershed Simulations. T. ASABE, 50(3), 885-900. 
Mualem,Y., 1976. A new model for predicting the hydraulic conductivity of unsaturated porous media. Water Resour. Res., 12(3), 513-522.

Nash, J.E., Sutcliffe, L.V. 1970. Riverflow forecasting through conceptual model. J. Hydrol., 273, 282-290.

Press, W.H., Teukolksky, S.A., Vetterling, W.T., Flannery, B.P., 1992. Numerical Recipes in Fortran - The art of scientific computing. Cambridge University Press, 934 pp.

Rana, G., Katerij, N., 2000. Measurement and estimation of actual evapotranspiration in the field under Mediterranean Climate: a review. Eur. J. Agron., 13, 125-153.

Soylu, M.E., Istanbulluoglu, E., Lenters, J.D., Wang, T., 2011. Quantifying the impact of groundwater depth on evapotranspiration in a semi-arid grassland region. Hydrol. Earth Syst. Sc., 15, 787-806.

Stenitzer, E., Diestel, H., Zenker, Th., Schwartengräber, R. 2007. Assessment of capillary rise from shallow groundwater by the simulation model SIMWASER using either estimated pedotransfer functions or measured hydraulic properties. Water Resour. Manag., 21, 1567-1584.

Supit, I., Hooijer, A.A., van Diepen, C.A., 1994. System Description of the Wofost 6.0 Crop Simulation Model Implemented in CGMS, Vol. 1: Theory and Algorithms. Joint Research Centre, Commission of the European Communities, EUR 15956 EN, Luxembourg, 146 pp.

Ten Berge, H.F.M, Metselaar, K., Jansen, M.J.W, San Agustin, E.M., Woodhead, T., 1995. The Sawah riceland hydrology model. Water Resour. Res., 31, 2721-2731.

Van Genuchten, M., 1980. A closed form equation for predicting the hydraulic conductivity of unsaturated soils. Soil Sci. Soc. Am. J., 44, 892-898.
Van Ittersum, M.K., Leffelaar, P.A., van Keulen, H., Kropff, M.J., Bastiaans, L., Goudriaan, J., 2003. On approaches and applications of the Wageningen crop models. Eur. J. Agron., $18,201-234$.

Wegehenkel, M., 2005. Validation of a soil water balance model using soil water content and pressure head data. Hydrol. Process., 19, 1139-1164.

Wegehenkel, M., Zhang, Y., Zenker, Th., Diestel, H., 2008. The use of lysimeter data for the test of two soil water balance models: A case study. J. Plant Nutr. Soil Sc., 171, $762-776$.

Willmott, C.J., 1982. Some comments on the evaluation of model performance. B. Am. Meteorol. Soc., 64, 1309-1313.

Wohlfahrt, G., Ischick, Chr., Thalinger, B., Hörtnagl, L., Obojes, N., Hammerle, A., 2010. Insights from independent evapotranspiration estimates for closing the energy balance: A grassland case study. VZJ, 9, 1025-1033.

Zenker, T., 2003. Grass reference evapotranspiration and bulk surface resistance. An analysis of the Penman-Monteith approach using lysimeter data obtained from a station located in Berlin. PhD thesis. Technical University of Berlin, pp. 147. (In German with English abstract.) http://edocs.tuberlin.de/diss/2003/zenker thomas.pdf

Received 8 November 2012 Accepted 12 February 2013 